\title{
Factitious administration of analogue insulin to a 2-year-old child
}

\author{
NEHAL THANAWALA, ${ }^{1}$ SARAH CHENEY, ${ }^{1}$ GWEN WARK, ${ }^{2}$ MARIO THEVIS, ${ }^{3}$ ANDREAS THOMAS, ${ }^{3}$ \\ WEBSTER MADIRA, ${ }^{4}$ VAITSA TZIAFERI, ${ }^{1}$ JAMES GREENING ${ }^{1}$
}

\section{Introduction}

Hypoglycaemia precipitated by factitious insulin administration presents in a very similar way to hypoglycaemia caused by hyperinsulinism (precipitated by conditions such as congenital hyperinsulinism and insulinoma). Diagnosis is based on circumstantial evidence and biochemical tests which include insulin and C-peptide levels.

Key words: factitious, insulin, child

\section{Case report}

A 2-year-old girl presented to the hospital with symptoms of weight loss, thirst and polyuria over the past 2 weeks. Her blood glucose level was high at $30.7 \mathrm{mmol} / \mathrm{L}$ and urine showed evidence of glycosuria of $500 \mathrm{mg} / \mathrm{dL}$ and ketonuria of $\geq 160 \mathrm{mg} / \mathrm{dL}$. Blood tests demonstrated an $\mathrm{HbA}_{1 c}$ level of $94 \mathrm{mmol} / \mathrm{mol}$ (reference range $20-43 \mathrm{mmol} / \mathrm{mol}$ ). She had a positive $1 \mathrm{~A} 2$ antibody level of $184 \mathrm{IU} / \mathrm{mL}$ (reference range $0-10 \mathrm{IU} / \mathrm{mL}$ ). Her anti-GAD antibody level was $<5 \mathrm{U} / \mathrm{mL}$ (reference range $0-10 \mathrm{U} / \mathrm{mL}$ ) and she had equivocal islet cell antibody levels. This pattern of clinical features and investigations is consistent with type 1 diabetes mellitus and probable autoimmune causation.

At diagnosis she was admitted to hospital and commenced on insulin injections to control her blood glucose levels. The family achieved the required competencies for education for selfmanagement of the child's diabetes. After discharge the diabetes team remained in regular contact with her parents over the telephone and face-to-face contacts in the outpatient clinic.

She was thereafter admitted to the hospital on day 109 postdiagnosis with hypoglycaemia. Her blood sugar on admission was low at $3 \mathrm{mmol} / \mathrm{L}$. Standard hypoglycaemia management

Department of Paediatrics, University Hospitals of Leicester NHS Trust, Leicester, UK

2 Royal Surrey County Hospital NHS Foundation Trust, Guildford, Surrey, UK

3 German Sport University Cologne, Center for Preventive Doping

Research/Institute of Biochemistry, Cologne, Germany

4 Department of Biochemistry, University Hospitals of Leicester NHS Trust, Leicester, UK

Address for correspondence: $\mathrm{Dr}$ James Greening Consultant Paediatrician, University Hospitals of Leicester NHS Trust, Leicester Royal Infirmary, Leicester LE1 5WW, UK

Tel: 01162586796

E-mail: james.greening@uhl-tr.nhs.uk

Br J Diabetes 2016;16:82-84

http://dx.doi.org/10.15277/bjd.2016.080
Figure 1. Blood sugar level trend on stopping insulin

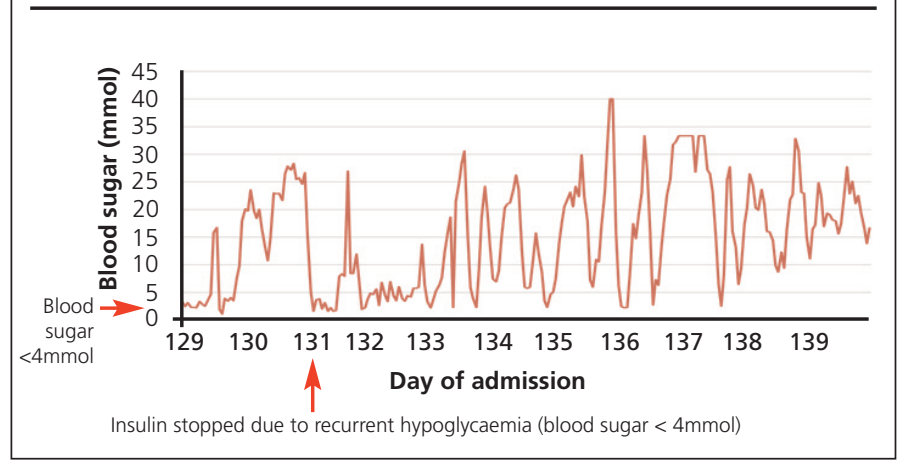

was insufficient and intravenous glucose infusion was necessary to establish normoglycaemia. Extensive re-education of her parents was done to ensure they had appropriate knowledge and awareness for treatment of acute onset hypoglycaemia.

She was then re-admitted 3 days later with a second hypoglycaemic episode not responding to repeated standard hypoglycaemic management. Her blood sugar on admission was low at 1.5 $\mathrm{mmol} / \mathrm{L}$. She again required intravenous dextrose to stabilise the blood glucose levels and was then discharged the following day.

The third re-admission for her hypoglycaemia occurred on day 128 post-diagnosis. Her parents reported that she had persistently low blood glucose over a $4 \mathrm{~h}$ period. They had failed to follow the management plan as recommended by the specialist diabetes team. Her blood sugar on admission was low at 2.0 $\mathrm{mmol} / \mathrm{L}$. Emergency resuscitation was required with glucose infusion to stabilise the blood sugar levels. Repeated concerted efforts to stop the infusion over the next 2-3 days failed due to wide fluctuations in her blood sugar levels (i.e. both high and low readings). As a result, on day 3 of her current admission it was decided to stop insulin administration completely for the time being, while closely monitoring her glucose levels. Insulin was stopped for 5 days. However, despite the best efforts, she was noted to have significant hypoglycaemia (Figure 1).

Specific blood investigations were performed during the hypoglycaemic event that revealed a high blood insulin concentration of $286 \mathrm{pmol} / \mathrm{L}$ and a low C-peptide of $<33 \mathrm{pmol} / \mathrm{l}$ (normal range 298-2350 pmol/L). The low C-peptide was consistent with the external administration of insulin as the molar ratio of insulin to C-peptide is $>1,{ }^{1}$ as opposed to beta cell recovery in a newly diagnosed young infant.

Second opinion was sought that corroborated our concern 
Figure 2. Extracted ion chromatograms

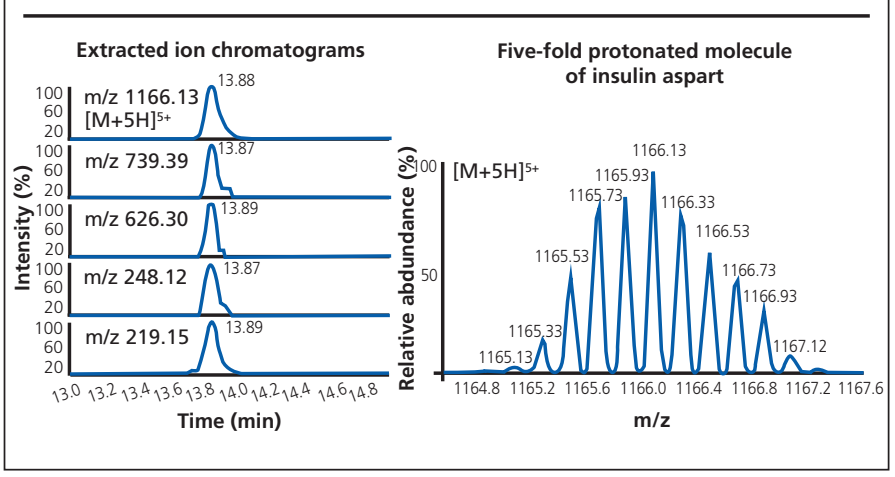

Figure 3. Blood sugar trend following removal of care from parents

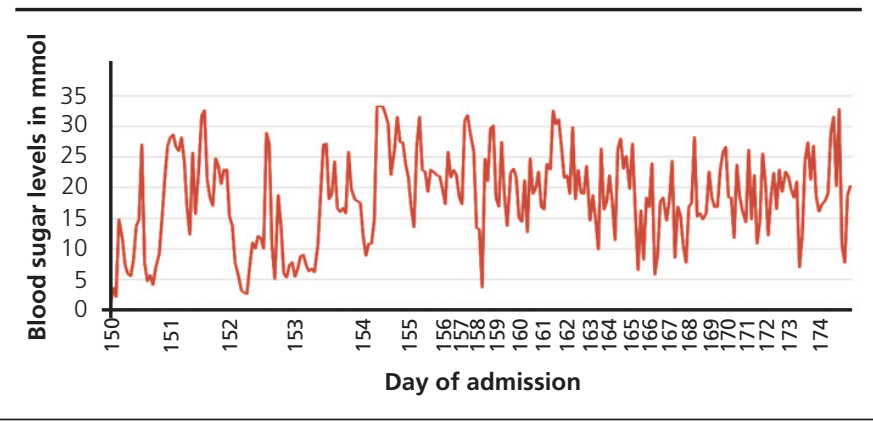

of third-party insulin administration. Safeguarding procedures were followed and all care was removed from the parents to conduct appropriate investigations and secure the safety of the child. Confirmatory tests were sent for expert external opinion. Repeat blood samples as requested were sent, which demonstrated high insulin levels of $270 \mathrm{pmol} / \mathrm{L}$ with a C-peptide level of $<94 \mathrm{pmol} / \mathrm{L}$. The insulin result obtained after polyethylene glycol (PEG) precipitation was $120 \mathrm{pmol} / \mathrm{L}$.

The measured insulin, C-peptide and the insulin result after PEG precipitation were not consistent with autoimmune-mediated hypoglycaemia (i.e. insulin antibodies binding insulin and releasing it at an inappropriate time to cause a low blood glucose), as the C-peptide level is suppressed and the insulin result after PEG precipitation is not low enough. In cases of autoimmune hypoglycaemia, the insulin result after PEG precipitation is $<10 \%$ of the non-treated insulin result. However, in this case it was $44 \%$.

Mass spectrometry was then performed to detect the type of insulin present in the patient's body during the hypoglycaemic event. This yielded a positive result for the insulin derivative aspart which contains the aminoacid substitution Pro(B28)Asp. The pharmacokinetic data were not consistent with the last recorded dose of short-acting insulin (insulin aspart; NovoRapid) given. Moreover, only human soluble insulin (Actrapid) charted for the patient at that time was being administered to the child in the hospital, and not insulin aspart, which is a modified synthetic and non-human insulin.

\section{Key messages}

- Factitious illness is uncommon with potentially serious co-morbidity

- Prompt investigations and management is essential

- Manage these patients in a hospital HDU setting for close clinical care

- Insulin to C-peptide ratio is a key marker for diagnosis

Also, the last dose of insulin aspart was administered $11 \mathrm{~h}$ prior to blood collection while the last dose of longer acting insulin detemir (Levemir) was given $59 \mathrm{~h}$ prior to blood collection. Pharmacokinetic data available suggest that both these types of insulin would have been expected to be eliminated from the body by the time of blood collection. The pharmacokinetics of the recorded doses of insulin administered in hospital led to the most likely probability that insulin was administered by a third party.

Extracted ion chromatograms of diagnostic precursor and product ions providing evidence for the presence of insulin aspart as determined in the child's sample is shown in Figure 2.2-4

From the five-fold charged molecule, the mass of the determined insulin can be accurately calculated, which matches that of insulin aspart. In addition, the product ions shown in the extracted ion chromatograms (739.4, 626.3, 248.1 and 219.1) unequivocally corroborate the identity of the substance.

Following removal of care from the parents to the hospital, only one further episode of transient hypoglycaemia was recorded which was not of the pattern of previous episodes. This transient hypoglycaemia was easily corrected by consumption of orange juice, compared with previous low blood sugars requiring intravenous dextrose (see Figure 3).

\section{Discussion}

This case demonstrates the difficulty in defining the medical causes of hypoglycaemia and subsequent exclusion of all other causes bar that of fabricated illness by third party insulin administration and its legal implications.

In this patient suspicion arose when, despite extensive re-training and education of the parents, the child had repeated admissions to the hospital with unexplained hypoglycaemia not responding to conservative management. During all three admissions, emergency intravenous resuscitation was deemed necessary. Moreover, despite being on intravenous dextrose, she continued to demonstrate periods of extreme glucose excursion with hyper- and hypoglycaemia. We excluded the endogenous causes for medical hypoglycaemia with normal glucose physiology, except for high insulin and low C-peptide levels, despite being off insulin for a considerable period of time. The insulin/C-peptide ratio should be carefully assessed in these cases as it can give vital clues to the underlying diagnosis. 
Factitious insulin administration is a difficult diagnosis to make; admission and consultation is usually necessary before the diagnosis can be confirmed. Hospitalisation may be warranted to keep the child safe from further abuse. The average length of time required to establish a diagnosis usually exceeds 6 months; ${ }^{5}$ in our case it was 3.5 months.

Managing a case of factitious insulin administration by proxy requires multidisciplinary team effort of doctors, nurses, child protection agencies, police and law, all working together in unison following strict child protection policy to ensure a correct chain of evidence and protection of the safety of the child.

\section{Conflict of interest None \\ Funding sources None}

\section{References}

1. Lebowitz MR, Blumenthal SA. The molar ratio of insulin to C-peptide: an aid to the diagnosis of hypoglycemia due to surreptitious (or inadvertent) insulin administration. Arch Intern Med 1993;153:650-5. http://dx.doi.org/10.1001/archinte.1993.00410050082011

2. Thomas A, Schänzer W, Delahaut P, Thevis M. Sensitive and fast identification of urinary human, synthetic and animal insulin by means of nano-UPLC coupled with high resolution/high accuracy mass spectrometry. Drug Test Anal 2009;1:219. http://dx.doi.org/10.1002/dta.35

3. Thomas A, Schänzer W, Thevis M. Determination of human insulin and its analogues in human blood using liquid chromatography coupled to ion mobility mass spectrometry (LC-IM-MS). Drug Test Anal 2014; 6:1125-32. http://dx.doi.org/10.1002/dta.1710

4. Thevis M, Thomas A, Delahaut P, Bosseloir A, Schänzer W. Qualitative determination of synthetic analogues of insulin in human plasma by immunoaffinity purification and liquid chromatography-tandem mass spectrometry for doping control purposes. Anal Chem 2005;77:3579-85. http://dx.doi.org/10.1021/ac050066i

5. Giurgea I, Ulinski T, Touati G, et al. Factitious hyperinsulinism leading to pancreatectomy: severe forms of Munchausen syndrome by proxy. Paediatrics 2005;116;e145. http://dx.doi.org/10.1542/peds.2004-2331

\section{cellñovo}

Mobile Diabetes Management

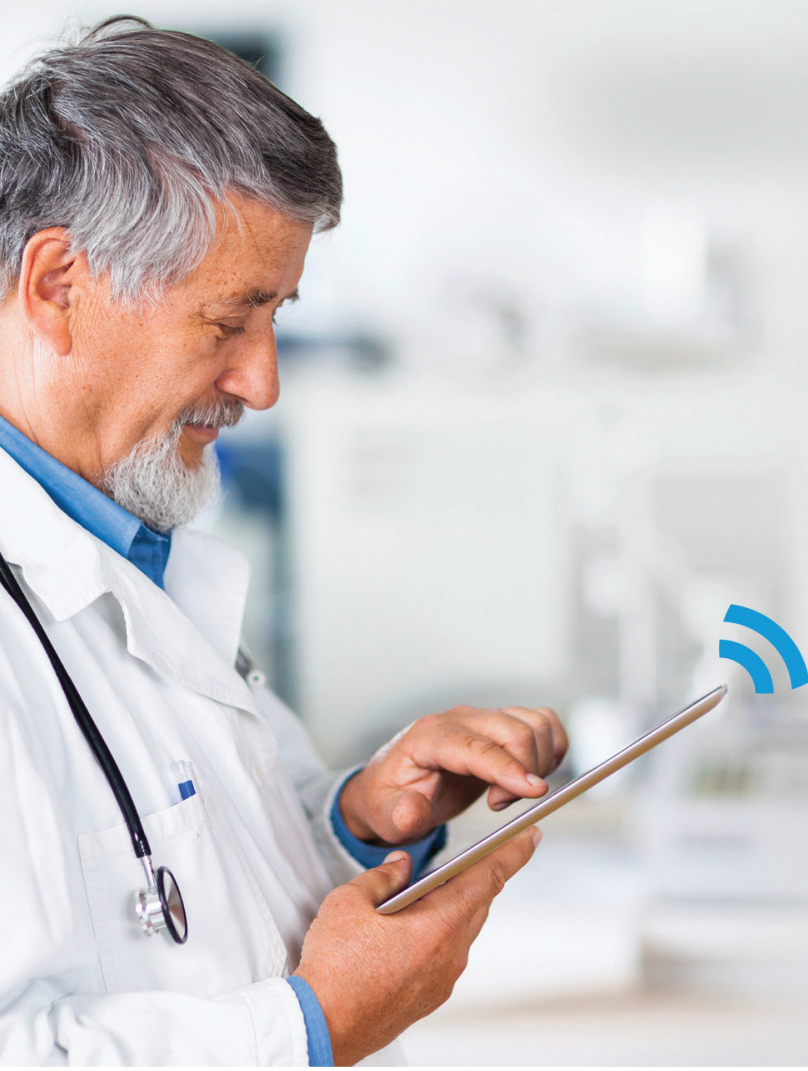

\section{CELLNOVO DIABETES MANAGEMENT SYSTEM MORE THAN JUST AN INSULIN PUMP}

\section{The Cellnovo System incorporates the real time transfer of patients' diabetes data via a mobile signal to a secure online platform}

- Blood Glucose, Insulin Delivery, Food and Activity data is captured automatically

- Removes the need to download patients' pumps

- View all your patients' data on one screen via the clinic portal

- Data is completely up to date and accurate

- Opens the possibilities for virtual clinics and remote consultations

\section{CONTACT}

08000258009

sales@cellnovo.com

www.cellnovo.com
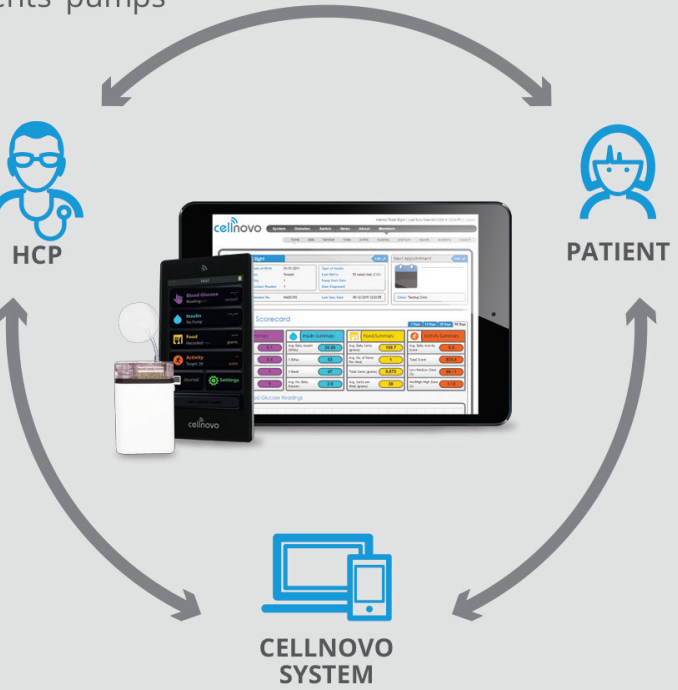

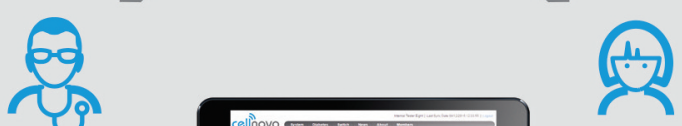

